\title{
Ramipril prevents hypersensitivity to phenylephrine in aorta from streptozotocin-induced diabetic rats
}

\author{
P. Murray ${ }^{1}$, B. Pitt ${ }^{2}$, R.C. Webb ${ }^{1}$ \\ ${ }^{1}$ Department of Physiology, The University of Michigan, Ann Arbor, Michigan, USA \\ ${ }^{2}$ Division of Cardiology, The University of Michigan, Ann Arbor, Michigan, USA
}

\begin{abstract}
Summary This study investigated the protective effect of the angiotensin converting enzyme inhibitor, ramipril, on endothelium-dependent responses in arteries from control (CON) and streptozotocin-induced (STZ) diabetic rats. Three hypotheses were tested: 1) there is an endothelium-dependent component to the increased alpha-adrenergic responsiveness characteristic of diabetes; 2) endothelium-dependent, acetylcholine-induced relaxation is attenuated in aorta from diabetic rats; and 3 ) ramipril ( $3 \mathrm{mg} / \mathrm{kg}$ daily in the food, $12-15$ weeks) will prevent functional vascular changes in diabetic rats. Vascular function was assessed in aortic rings using standard muscle bath procedures for measurement of isometric force. Sensitivity to phenylephrine was increased in aortic rings from diabetic compared to control values $\left[\mathrm{pD}_{2}\right.$ values (- $\log$ $\left.\left.\mathrm{ED}_{50}\right): \quad \mathrm{CON}=6.22 \pm 0.12, \quad \mathrm{STZ}=7.54 \pm 0.11\right)$, and removal of the endothelium (-Endo) increased phenylephrine sensitivity (CON-Endo $=7.40 \pm 0.11$, STZ-
\end{abstract}

Endo $=8.32 \pm 0.18$ ). The magnitude of the shift in responsiveness following endothelium removal was greatest in control rats. Ramipril treatment (Ram) partially normalized phenylephrine responsiveness in intact $(\mathrm{STZ}+\mathrm{Ram}=6.55 \pm 0.11)$ and denuded (STZEndo $+\operatorname{Ram}=7.75 \pm 0.10$ ) vessels. Vasodilatation to acetylcholine and nitroglycerin was not altered in diabetic rats nor was it affected by ramipril treatment. Diabetes increases contractile sensitivity to phenylephrine but not to vasodilators and chronic ramipril treatment prevents this increase in contractile sensitivity. Ramipril treatment did not alter the hyperglycaemic condition induced by streptozotocin. The changes in phenylephrine sensitivity appear to involve an endothelial and a smooth muscle component. [Diabetologia (1994) 37: 664-670]

Key words Endothelium, acetylcholine, angiotensin converting enzyme inhibitor, vascular smooth muscle.
Microvascular and macrovascular changes are frequent, complicating features of diabetes mellitus $[1,2]$ and approximately $75 \%$ of the mortality in diabetes is a direct result of these complications [3]. In addition, diabetes also predisposes humans to multiple cardiovascular diseases including hypertension $[4,5]$, athe-

Received: 4 November 1993

and in revised form: 31 January 1993

Corresponding author: R. Clinton Webb, Ph.D., Department of Physiology, The University of Michigan, Medical Science Building II, 7813, Ann Arbor, MI 48109-0622, USA

Abbreviations: STZ, streptozotocin; ACE, angiotensin converting enzyme; $\mathrm{EC}_{50}$, agonist concentration resulting in a half maximal contraction; $\mathrm{NO}$, nitric oxide. rosclerosis, and thrombosis $[6,7]$. Thus, the mortality rate due to cardiovascular diseases is significantly higher in the diabetic population [8] and the common pathway appears to involve alterations in vascular function [8-13]. It has been demonstrated that diabetes results in damage to the endothelial layer $[13,14]$ that leads to changes in vascular reactivity $[11,13,14]$. However, there is considerable variability in the literature concerning the direction of change in response to vasoactive agents (Table 1). For example, Agrawal and McNeill [9] and Chang and Stevens [15] report that diabetes increases vascular responsiveness to alphaadrenergic agonists. Pfaffman and co-workers $[8,13$, 16] show data to indicate a decrease in vascular reactivity to phenylephrine in diabetes. Finally, Durante et al. [10] and Mulhern and Docherty [17] show no change in 
Table 1. Vascular reactivity in diabetic rats

\begin{tabular}{|c|c|c|c|c|}
\hline Agonist & $\begin{array}{l}\text { Responsiveness } \\
\text { (Relative to Control) }\end{array}$ & Artery Tested & Diabetic Model & References \\
\hline \multirow[t]{3}{*}{ Phenylephrine } & Unchanged & Aorta & STZ, genetic & Durante et al. [10], Kyoung et al. [18] \\
\hline & Increased & Aorta, mesenteric & STZ & $\begin{array}{l}\text { Agrawal, McNeil [9], Chang, Stevens [15], } \\
\text { Kyoung et al. [18] }\end{array}$ \\
\hline & Decreased & Aorta & STZ & Pfaffman et al. $[8,13,16]$ \\
\hline \multirow[t]{3}{*}{ Acetylcholine } & Unchanged & Aorta, mesenteric & STZ, Alloxan & $\begin{array}{l}\text { Fortes et al. [19], Kappagoda et al. [20], } \\
\text { Kyoung et al. [18], Mulhern, Docherty [17], } \\
\text { Wakabayashi et al. [21] }\end{array}$ \\
\hline & Increased & Aorta & Alloxan & Altan et al. [6] \\
\hline & Decreased & Aorta, basilar & STZ, genetic & $\begin{array}{l}\text { Altan et al. [6], Durante et al. [10], Kamata et } \\
\text { al. [11], Kappagoda et al. [20], Kyoung et al. } \\
\text { [18], Mayhan [22]; Oyama et al. [23], Pieper et } \\
\text { al. [24, 25] }\end{array}$ \\
\hline Nitroglycerin & Unchanged & Aorta, cerebral & STZ & $\begin{array}{l}\text { Matsuzaki, Sakanashi [25], Mayhan [22], } \\
\text { Pieper et al. }[24,25]\end{array}$ \\
\hline
\end{tabular}

Vascular reactivity was assessed as isometric force generation in isolated preparations using standard muscle bath techniques

response to vasoconstrictors in diabetes. Vasodilator responsiveness to the endothelium-dependent agonist, acetylcholine, has been observed to be either decreased or unchanged in diabetic rats whereas responsiveness to nitroglycerin is not altered in this disease state (Table 1). Aithough part of this variability between studies is probably due to differences in the diabetic state, it is partly probably also due to differences in procedure (endothelium removal, ring vs strip preparations, etc.) and the strain, gender and age of rats used.

Clozel et al. [27] suggested that ACE inhibitors serve a protective function in the vasculature by attenuating the morphologic changes in the endothelium which are associated with hypertension. Related research has indicated that ramipril prevents attenuation of endothelium-dependent responsiveness in aorta from rabbits receiving an atherogenic diet [28]. The present study investigated the protective effect of the ACE inhibitor, ramipril, on endothelium-dependent responses in rings of thoracic aorta from control (CON) and STZ-induced diabetic rats. Three hypotheses were tested: 1) there is an endothelium-dependent component to the increased alpha-adrenergic responsiveness characteristic of diabetes; 2) endothelium-dependent, acetylcholine-induced relaxation is attenuated in aorta from diabetic rats; and 3) chronic ramipril treatment will prevent functional vascular changes in diabetic rats.

\section{Materials and methods}

Animals: Male Wistar-Kyoto rats $(111 \pm 4 \mathrm{~g}, n=30)$ were obtained from a University of Michigan colony and randomly divided into four groups: control $(\mathrm{CON}, n=5)$, ramipril-treated control (CON + Ram, $n=5)$, untreated diabetic $(\mathrm{STZ}, n=10)$, and ramipril-treated diabetic (STZ + Ram, $n=10$ ). Diabetes was induced with i.p. injections of STZ, $65 \mathrm{mg} \cdot \mathrm{kg}^{-1}$ in citrate buffer $(\mathrm{pH}=4)$. Age-matched control rats received the buffer alone. Following injection of STZ (3-5 days), diabetes was assessed by the presence of glucose $(\geq 0.33 \mathrm{mmol} / \mathrm{l})$ in the urine using Chemstrip uGK urine test strips (Boehringer Mannheim, Indianapolis, Ind., USA). At the end of the dietary intervention, plasma levels of glucose (non-fasting state) were determined. Systolic blood pressures were measured in conscious rats by the tail-cuff method (pneumatic transducer).

Treatment period: One week after STZ injections, the untreated groups were provided with normal rat chow. The ramipril groups were given food containing $0.0025 \%$ ramipril. The average daily dose of ramipril received by the STZ + Ram rats was $3 \mathrm{mg} / \mathrm{kg}$ body weight. All groups received food and water ad libitum, and all rat chow was prepared by Purina Mills Inc. (St. Louis, MO, USA). The treatment period was $12-15$ weeks.

Tissue preparation: Thirteen to fifteen weeks after induction of diabetes, rats were anaesthetized with $65 \mathrm{mg} / \mathrm{kg}$ sodium pentobatbital (i.p.). Blood (3-5 ml) was withdrawn from a venous catheter (jugular vein) into heparinized syringes for determination of plasma glucose levels using an immobilized enzyme membrane coupled with a hydrogen peroxide sensor (model $23 \mathrm{~A}$; Glucose Analyzer, Yellow Springs Instrument Co., Inc. Yellow Springs, Ohio, USA). The thoracic cavity was opened and the thoracic aorta was rapidly excised and placed in cold physiological saline solution containing (mmol/l): $\mathrm{NaCl}(130), \mathrm{KCl}(4.7), \mathrm{KH}_{2} \mathrm{PO}_{4}$ (1.18), $\mathrm{MgSO}_{4}-7 \mathrm{H}_{2} \mathrm{O}(1.17), \mathrm{NaHCO}_{3}$ (14.9), dextrose (5.5), $\mathrm{CaNa}_{2}$ EDTA (0.026) and $\mathrm{CaCl}_{2}(1.6)$. Excess connective tissue and fat was removed and each vessel was cut into two $5-\mathrm{mm}$ rings. In one vessel segment from each rat, the endothelium was removed by gently rubbing the lumen of these vessels with a cotton swab. Rings were threaded with stainless steel wires and attached to a fixed support at one end and to a force transducer (Grass FT.03, (Grass Instruments, Quincy, Mass., USA)) at the other end. Tissues were suspended in 50-ml jacketed organ baths containing physiological saline solution maintained at $37^{\circ} \mathrm{C}$ and aerated with $95 \% \mathrm{O}_{2}, 5 \% \mathrm{CO}_{2}$.

Tissues were equilibrated for $2 \mathrm{~h}$ under a passive force $(\sim 3 \mathrm{~g})$ that was determined to be optimal for maximal force generation to phenylephrine $(10 \mu \mathrm{mol} / \mathrm{l})$. Tissues were washed every $30 \mathrm{~min}$. During the equilibration period, the tissues were exposed to $10^{-5}$ 
Table 2. Blood pressures and body weights

\begin{tabular}{llll}
\hline Experimental group & $\begin{array}{l}\text { Body weight } \\
(\mathrm{g})\end{array}$ & $\begin{array}{l}\text { Systolic blood pressure } \\
(\mathrm{mm} \mathrm{Hg})\end{array}$ & $\begin{array}{l}\text { Plasma glucose } \\
(\mathrm{mg} / \mathrm{dL})\end{array}$ \\
\hline Untreated Control $(n=5)$ & $450 \pm 17$ & $135 \pm 3$ & $186 \pm 22$ \\
Ramipril-treated Control $(n=5)$ & $412 \pm 32$ & $112 \pm 10^{\mathrm{b}}$ & $166 \pm 12$ \\
Untreated Diabetic $(n=10)$ & $239 \pm 12^{\mathrm{a}}$ & $148 \pm 7^{\mathrm{b}}$ & $543 \pm 60^{\mathrm{a}}$ \\
Ramipril-treated diabetic $(n=10)$ & $355 \pm 17^{\mathrm{a}}$ & $106 \pm 4$ & $566 \pm 91^{\mathrm{a}}$ \\
\hline
\end{tabular}

Values are presented as the mean $\pm \mathrm{SEM}$.

a Statistical significant difference compared to all other groups $(p<0.05)$

${ }^{\mathrm{b}}$ Statistical significant difference between untreated groups and their respective ramipril-treated groups $(p<0.05)$

Table 3. Shift factors and $\mathrm{pD} 2$ values for phenylephrine

\begin{tabular}{llll}
\hline Experimental group & + Endothelium & -Endothelium & Shift factor \\
\hline Control $(n=5)$ & $6.22 \pm 0.12$ & $7.40 \pm 0.11^{\mathrm{c}}$ & $19.0 \pm 1.8$ \\
Ramipril-treated control $(n=5)$ & $6.37 \pm 0.04$ & $7.22 \pm 0.20^{\mathrm{c}}$ & $13.4 \pm 3.1$ \\
Untreated diabetic $(n=10)$ & $7.54 \pm 0.11^{\mathrm{a}}$ & $8.32 \pm 0.18^{\mathrm{a}, \mathrm{c}}$ & $10.9 \pm 2.2^{\mathrm{a}}$ \\
Ramipril-treated diabetic $(n=10)$ & $6.55 \pm 0.11^{\mathrm{b}}$ & $7.75 \pm 0.10^{\mathrm{b}, \mathrm{c}}$ & $\cdot$ \\
\hline
\end{tabular}

Values are presented as the mean + S. E. M. a Statistical significant difference between diabetic and control groups $(p<0.05)$.

${ }^{b}$ Statistical significant difference between untreated and rami- pril-treated groups $\left(p<0.05 .{ }^{c}\right.$ Statistical difference between endothelium intact ( + Endothelium) and endothelium denuded ( - Endothelium) preparations $(p<0.05)$ $\mathrm{mol} / \mathrm{l}$ indomethacin to inhibit cyclooxygenase activity since tissue damage during isolation can increase the activity of this enzyme [29]. After the equilibration period, the aortic rings were contracted with a submaximal concentration of phenylephrine $\left(3 \times 10^{-8} \mathrm{~mol} / \mathrm{l}\right)$, and relaxation to acetylcholine $\left(10^{-7} \mathrm{~mol} / \mathrm{l}\right)$ was used to test for the presence of the endothelium. The rings were then washed and allowed to relax to baseline levels.

Concentration-response curves: Concentration response curves for phenylephrine $\left(10^{-9}\right.$ to $\left.3 \times 10^{-5} \mathrm{~mol} / \mathrm{l}\right)$ were obtained by adding cumulative concentrations directly to the muscle baths. Contractile responses were evaluated as a percentage of maximal contraction. Concentration response curves to vasodilators were obtained by contracting the vessel with an $\mathrm{EC}_{50}$ concentration of phenylephrine and adding increasing concentrations of acetylcholine $\left(10^{-9}\right.$ to $\left.3 \times 10^{-5} \mathrm{~mol} / \mathrm{l}\right)$ or nitroglycerin $\left(10^{-9}\right.$ to $\left.3 \times 10^{-5} \mathrm{~mol} / \mathrm{l}\right)$. Vasodilator responses are reported as a percentage of the phenylephrine-induced contraction.

Drugs: Acetylcholine chloride, indomethacin, phenylephrine hydrochloride, and STZ were purchased from Sigma Chemical Company (St. Louis, Mo., USA). Nitroglycerin and sodium pentobarbital were purchased from the University of Michigan Hospital Pharmacy (Ann Arbor, Mich., USA).

Statistical analysis: Data are presented as mean \pm SEM. Sensitivity to phenylephrine is evaluated as the $\mathrm{pD} 2\left(-\log \mathrm{EC}_{50} ;[30]\right)$. $\mathrm{EC}_{50}$ values were calculated using non-linear regression analysis. A shift factor was calculated according to the following formula to estimate the magnitude of change in phenylephrine sensitivity following endothelium removal:

shift factor $=$

$-\frac{\left(\mathrm{pD}_{2} \text { for intact segment }\right)-\left(\mathrm{pD}_{2} \text { for denuded segment }\right)}{\mathrm{pD}_{2} \text { for intact segment }} \times 100$

Student's $t$-tests were used to determine statistical significance $(p<0.05)$. When multiple Student's $t$-tests were used, the Bonferroni correction was utilized.

\section{Results}

As shown in Table 2, body weights were significantly reduced in the STZ compared to the CON group. The rats in the STZ + Ram group had significantly reduced weights compared to the CON group but greater weights than the STZ group. There was no significant difference between the CON group and the CON + Ram group. Plasma glucose levels were elevated in both diabetic rat groups compared to the control groups. Plasma glucose levels in the STZ + Ram group were not statistically different from those in the STZ rat group.

Table 2 also shows the average systolic blood pressure (in $\mathrm{mm} \mathrm{Hg}$ ) for all rat groups. The STZ group tended to have higher pressures than the CON group, but the difference was not statistically significant $(p=0.06)$. The $\mathrm{STZ}+\mathrm{Ram}$ group and the $\mathrm{CON}+\mathrm{Ram}$ group both had significantly lower systolic blood pressures than either the CON group or the STZ, respectively. Similarly, there was no significant difference in the average blood pressure of the CON + Ram group and the STZ + Ram group.

Cumulative addition of phenylephrine, an $\alpha_{1}$ adrenergic agonist $\left(10^{-9}\right.$ to $\left.10^{-5} \mathrm{~mol} / \mathrm{l}\right)$, to the muscle bath caused contraction in all aortic segments (Fig. 1, top and bottom; $\mathrm{pD}_{2}$ values reported in Table 3). Arteries from untreated diabetic rats were more sensitive to phenylephrine as evidenced by the leftward shift in the concentration response curve relative to control values. For groups with intact endothelium (Fig. 1 and Table 3), phenylephrine had a significantly greater potency $\left(\mathrm{pD}_{2}\right)$ in aortic rings from $\mathrm{STZ}$ than from $\mathrm{CON}$ animals. There were no significant differences 

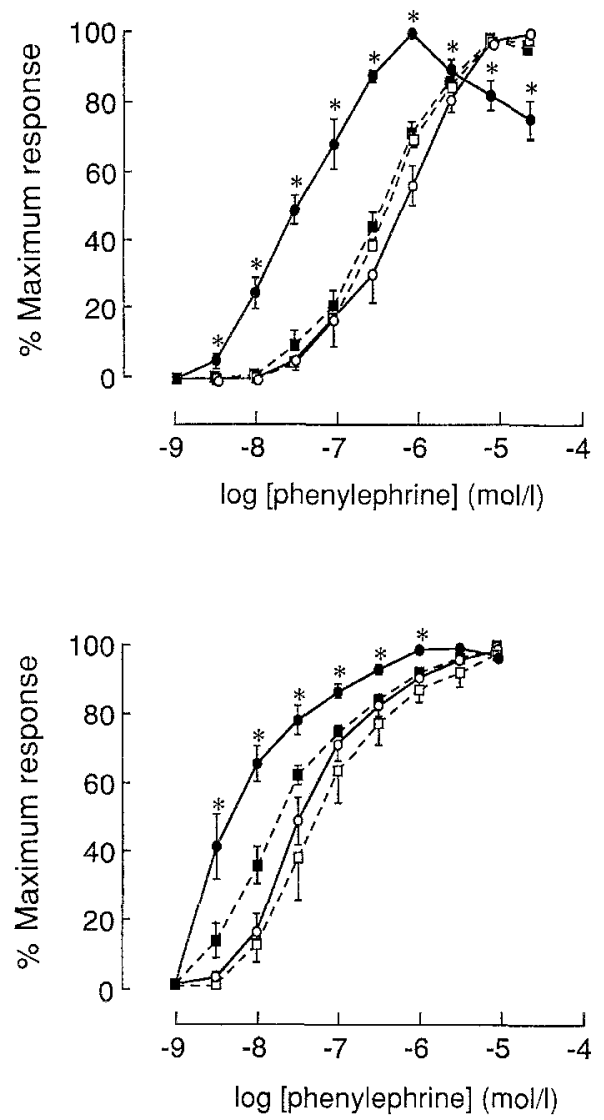

Fig. 1. Cumulative concentration-response measurements to phenylephrine in tissues with intact endothelium (top) and tissues with endothelium removed (bottom). Values represent the mean \pm SEM. Arteries from diabetic rats (endothelium intact and removed) demonstrated a significantly higher sensitivity to phenylephrine when compared to the control group $(* p<0.05)$. The concentration-response curves for the control group and the ramipril-treated diabetic group were not significantly different. Untreated control, -0 - ; ramipril-treated control, $--\square--$; untreated diabetic, $-\longrightarrow$; ramipril-treated diabetic, $--\mathbf{a}_{--}$

among the CON group, the CON + Ram $=6.37 \pm 0.04$, or the STZ + Ram groups. Maximal force development (in $\mathrm{mg}$ ) to phenylephrine in the various groups was: endothelium-intact segments $(\mathrm{CON}=1,116 \pm 33$; $\mathrm{CON}+\mathrm{Ram}=1,204 \pm 44 ; \mathrm{STZ}=1,153 \pm 229 ; \mathrm{STZ}+$ Ram $=1,480 \pm 96$ ); endothelium removed segments $(\mathrm{CON}=1,755 \pm 335 ; \mathrm{CON}+\mathrm{Ram}=1,975 \pm 314 ; \mathrm{STZ}$ $=1,725 \pm 288$; STZ + Ram $=2266 \pm 196)$. The maximal force developed by denuded segments was statistically greater for intact segments in all rat groups $(p<0.05)$.

For groups in which the endothelium was removed (Fig. 1 and Table 3), the untreated diabetic group (STZ-Endo) demonstrated significantly higher $\mathrm{pD}_{2}$ values than the control group (CON-Endo), the ramipril-treated group (CON + Ram-Endo) and the ramipril-treated diabetic group (STZ + Ram-Endo). The $\mathrm{pD}_{2}$ value for the $\mathrm{STZ}+\mathrm{Ram}$-Endo group was significantly higher than that of the CON + Ram-Endo group but lower than that of the STZ-Endo group. There were no significant differences in $\mathrm{pD}_{2}$ values between the CON group and the CON + Ram group. Because endothelium removal significantly increased the $\mathrm{pD}_{2}$ values for all groups, and the magnitude of this change was greatest for the CON group and lowest for the STZ alterations in endothelium function may also play a role in diabetes-induced hypersensitivity to phenylephrine. This conclusion is also supported by the analysis of shift factors which reflect the change in phenylephrine sensitivity following removal of the endothelium (Table 3). The shift factor for aortae from untreated diabetic rats was smaller than in those from control rats, indicating that the endothelium blunts phenylephrine sensitivity less in diabetes. The shift factor in ramipril-treated diabetic rats was statistically greater than untreated diabetic rats and closer in magnitude to that of untreated control rats indicating that ramipril prevented the change in sensitivity primarily through the normalization of the endothelium that blunts phenylephrine sensitivity.

Aortic segments with and without endothelium were contracted with half-maximal concentrations of phenylephrine, and subsequent addition of increasing concentrations of nitroglycerin $\left(3 \times 10^{-8}\right.$ to $\left.3 \times 10^{-6} \mathrm{~mol} / \mathrm{l}\right)$ caused relaxation in all aortic segments (Fig. 2). In aortic rings with intact endothelium (Fig. 2, top), there were no significant differences in the relaxation response to nitroglycerin at any concentration of the drug for any of the rat groups. For groups in which the endothelium was removed (Fig. 2, bottom), the aortic rings from the diabetic group demonstrated an increased sensitivity to nitroglycerin at concentrations of $3 \times 10^{-9} \mathrm{~mol} / \mathrm{l}$ and $10^{-8}$ $\mathrm{mol} / \mathrm{l}$ compared tovalues in the CON group. Only at $10^{-8}$ $\mathrm{mol} / \mathrm{l}$ nitroglycerin was there a significant difference in relaxation to nitroglycerin in aortic rings from control and ramipril-treated diabetic rats.

Aortic segments with intact endothelium were contracted with half-maximal concentrations of phenylephrine. The subsequent addition of increasing concentrations of acetylcholine $\left(3 \times 10^{-8}\right.$ to $\left.3 \times 10^{-6} \mathrm{~mol} / \mathrm{l}\right)$ caused relaxation in all aortic segments (Fig. 3). Although not shown on the graph, at concentrations of $10^{-7} \mathrm{~mol} / 1$ and $3 \times 10^{-7}$, aortic rings from the ramipriltreated control group demonstrated greater responsiveness to acetylcholine than the rings from the untreated diabetic group. The concentration response curves for the control and diabetic group were not significantly different.

\section{Discussion}

The results showed that sensitivity to phenylephrine was increased in diabetic compared to control rats and removal of the endothelium increased phenylephrine sensitivity in both groups. Ramipril treatment normalized the increased vascular sensitivity to phenylephrine in vessels with intact endothelium and partially 

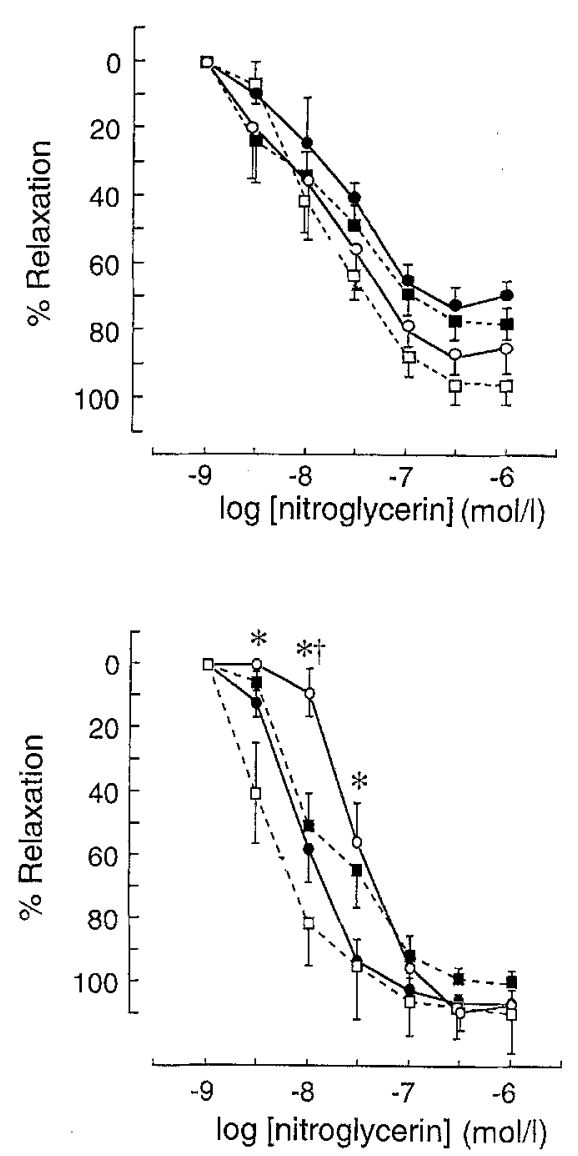

Fig. 2. Cumulative concentration-response measurements to nitroglycerin for arteries with endothelium intact (top) and endothelium removed (bottom). Values represent the mean $\pm S E M$. Relaxation to nitroglycerin was calculated as percent relaxation of force developed in response to an approximate half-maximal contraction to phenylephrine. For groups in which the endothelium was removed (bottom), the aortic rings from the diabetic group demonstrated an increased response to nitroglycerin only at concentrations of $3 \times 10^{-9} \mathrm{~mol} / 1$ and $10^{-8} \mathrm{~mol} / 1$. In arteries with intact endothelium and endothelium removed, concentration response curves for control and diabetic tissues were not significantly different. Untreated control, $-0-$; ramipril-treated control, $--\square--$; untreated diabetic, - - ; ramipril-treated diabetic, $--\mathbf{-}--$

normalized sensitivity in endothelium-denuded vessels. Ramipril also lowered blood pressure in normal and diabetic rats and partially restored body weights in diabetic rats. In contrast, vasodilatation to acetylcholine and nitroglycerin was not different between normal and diabetic rats. The ACE inhibitor did not alter the STZ-induced hyperglycaemia. These findings suggest that diabetes increases contractile sensitivity to phenylephrine but not relaxation to acetylcholine or nitroglycerin. More importantly, chronic ramipril treatment prevents the altered contractile sensitivity in diabetes.

Although short-term diabetes did not have a significant effect on blood pressure, ramipril treatment significantly reduced systolic blood pressure in normal and diabetic rats. There are several mechanisms by which

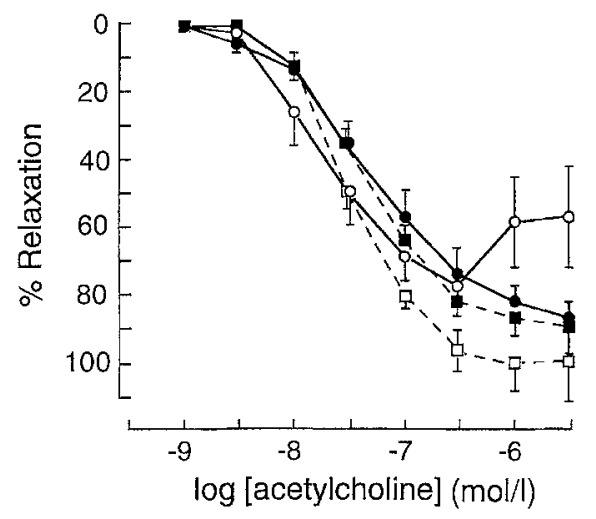

Fig.3. Cumulative concentration response measurements to acetylcholine in tissues with intact endothelium. Relaxation to acetylcholine was calculated as percent relaxation of force developed in response to an approximate half-maximal contraction to phenylephrine. Values represent the mean \pm SEM. Concentration response curves for control and diabetic tissues were not significantly different. Arteries without endothelium did not relax to acetylcholine. Untreated control, -O-; ramipriltreated control, $--\square--$; untreated diabetic, - - ; ramipriltreated diabetic, $-\cdots--$

ramipril might lower systolic blood pressure. By inhibition of the breakdown of bradykinin, ACE inhibitors potentiate its direct vasodilator effects [31]. Further, Momose et al. [32] reported that bradykinin inhibits secretion of the vasoconstrictor endothelin- 1 from endothelial cells. ACE inhibitors also reduce blood pressure by stimulating NO release from the vascular endothelium $[33,34]$ and by lowering plasma levels of angiotensin II, ACE inhibitors reduce the release of norepinephrine from adrenergic nerve endings in the blood vessel wall.

Because diabetic rats had increased daily food consumption (in grams eaten and grams $/ \mathrm{kg}$ body mass), their reduced body weights appear to be the result of a metabolic abnormality. The difference in body weights between the diabetic rats and the ramipril-treated diabetic rats $(\mathrm{STZ}=239 \pm 12 \mathrm{~g}, \mathrm{STZ}+\mathrm{Ram}=355 \pm 17$ g) suggests that chronic ramipril treatment partially normalized this metabolic abnormality. This effect was not associated with plasma glucose levels; ramipril did not lower plasma glucose levels in either the untreated control rats or the STZ rats.

Phenylephrine sensitivity was increased in the aorta with intact endothelium from diabetic rats. A lack of significant difference between phenylephrine $\mathrm{pD}_{2}$ values in aorta from the untreated control group, the ramipriltreated control group or the ramipril-treated diabetic group, indicates that ramipril prevents diabetes-induced alterations in phenylephrine sensitivity. Our results are consistent with studies which have reported increased vascular sensitivity to phenylephrine in diabetic animals $[9,15]$ and in tissues from which the endothelium has been removed $[35,36]$. Removal of the endothelium significantly increased phenylephrine sensitiv- 
ity in all groups possibly by abolishing the effect of basal NO release by the endothelium. However, the decreased shift in the diabetic group compared to the control groupsuggests that the increase in sensitivity to phenylephrine may be partially related to a diabetes-induced change in the endothelium. Previous research has supported the concept that NO plays a major role in the regulation of vascular tone [37] and that its release may be attenuated in diabetes. ACE inhibitors have been reported to stimulate the release of vasodilator NO from the vascular endothelium $[27,34]$ and this may explain the normalizing effect of ramipril on phenylephrine sensitivity in endothelium-intact vessels.

However, if increased phenylephrine sensitivity in diabetes were caused solely by decreased production of endothelium-dependent vasodilators, termination of vasodilator production by removing the endothelium should completely eliminate the differences in smooth muscle sensitivity to phenylephrine between the diabetic and the control groups. In our study, however, vessels from diabetic rats maintained increased phenylephrine sensitivity relative to control groups even after endothelium removal, and the greatest magnitude of change was observed in the control group while the untreated diabetic group demonstrated the smallest alteration in sensitivity. A number of researchers have demonstrated that vascular smooth muscle as well as endothelium is equipped with the cellular machinery necessary for NO synthesis [38-40]. It is therefore possible that increased sensitivity to phenylephrine in tissues from diabetic rats is partially due to decreased NO production by smooth muscle. This hypothesis is somewhat speculative but, if diabetes impairs this function, then it is possible that ACE inhibitors such as ramipril could reverse the resulting hypersensitivity to phenylephrine by stimulating NO production in the smooth muscle cell.

Our data confirm previous reports $[22,24,26]$ indicating that diabetes does not significantly influence endothelium-independent vasodilatation by nitroglycerin. Because nitroglycerin releases NO independently of NO synthase and acts directlyon guanylate cyclase in the smooth muscle, the observed increase in reactivity to phenylephrine in aortae from diabetic rats does not appear to be due to a reduced sensitivity to NO. Furthermore, because diabetes did not affect vasodilatation to acetylcholine, it appears that short-term diabetes does not impair agonist-stimulated NO release by the endothelium. This does not disprove the hypothesis that short-term diabetes influences release of NO by the endothelium, but it does suggest that if endothelium-modulated release of NO is affected by short-term diabetes, then it appears to be at the basal level. Our data are also supported by reports that short-term diabetes does not significantly alter endothelium-mediated reactivity to acetylcholine $[17,19-21]$. Somewhat unrelated yet important, these observations indicate that responsiveness to acetylcholine may not be an accurate measure of a defective contribution of the endothelium to vascular changes in a disease state such as diabetes.

Diabetes may also affect sensitivity to phenylephrine by influencing membrane permeability, and ACE inhibition could serve a protective function against membrane defects. For example, in smooth muscle cells from hypertensive rats, ACE inhibition has been found to improve impaired transport in calcium channels [41] and membrane permeability for sodium [42]. It is not clear from our study how ramipril might influence these diabetes-induced changes in membrane permeability.

ACE inhibition may also have normalized phenylephrine responsiveness by decreasing receptor affinity to phenylephrine in aorta from diabetic rats. However, our results showed no change in response to phenylephrine in arteries from healthy rats treated with ramipril. These data are supported by Rosendorff et al. [43] who reported that cilazapril, an $\mathrm{ACE}$ inhibitor, does not affect the affinity of phenylephrine for $\alpha$-adrenergic receptors. Similarly, Tierney et al. [44] reported no effect of enalaprilat on responses to phenylephrine in segments from rat tail arteries.

In conclusion, diabetes increases contractile sensitivity to phenylephrine but not to the vasodilators nitroglycerin or acetylcholine. The increased sensitivity to phenylephrine in diabetes is the result of changes in both the endothelium and the smooth muscle. Chronic ramipril treatment prevents the altered contractile sensitivity in diabetes by an action on both the endothelium and smooth muscle. This action of the ACE inhibitor on vascular reactivity is not associated with the hyperglycaemia which characterizes the diabetic state.

Acknowledgements. This work was supported by a grant from the National Institutes of Health (HL-18575).

\section{References}

1. Doria A, Fioretto P, Avogaro A et al. (1991) Insulin resistance is associated with high lithium-sodium counter-transport in essential hypertension. Am J Physiol 261: E684-E691

2. Ganda $O(1980)$ Pathogenesis of macrovascular disease in the human diabetic. Diabetes 29: 931-942

3. Ross H, Bernstein G, Rifkin H (1983) Relationship of metabolic control of diabetes mellitus to long-term complications in diabetes mellitus, theory and practice, 3 rd edn. Medical Examination Publication, New York, p 907

4. Christlieb A (1973) Diabetes and hypertensive vascular disease. Mechanisms and treatment. Am J Cardiol 32: 592-606

5. Pfaffman M, Dudley P, Prater A (1983) Relationship between untreated and insulin-treated diabetes and vascular relaxation. Arch Int Pharmacodyn Ther 266: 131-143

6. Altan V, Karasu C, Ozuari A (1989) The effects of type-1 and type-2 diabetes on endothelium-dependent relaxation in rat aorta. Pharmacol Biochem Behavior 33: 519-522

7. Garcia M, McNamara P, Gordon I, Kannell W (1974) Morbidity and mortality in diabetics in the Framingham population: sixteen year follow up study. Diabetes 23: 104-111 
8. Pfaffman M (1980) The effects of streptozotocin-induced diabetes and insulin-treatment on the cardiovascular system of the rat. Res Commun Chem Pathol Pharmacol 28: 27-41

9. Agrawal D, McNeill J (1987) Vascular responses to agonists in rat mesenteric artery from diabetic rats. Can J Physiol Pharmacol 65: 1484-1490

10. Durante W, Sen A, Sunahara F (1988) Impairment of endothelium-dependent relaxation in aortae from spontaneously diabetic rats. Br J Pharmacol 94: 463-468

11. Kamata K, Miyata N, Kasuya Y (1989) Impairment of endothelium-dependent relaxation and changes in levels of cyclic GMP in aorta from streptozotocin-induced diabetic rats. Br J Pharmacol 97: 614-618

12. Kamata K, Miyata N, Kasuya Y (1989) Involvement of endothelial cells in relaxation and contraction responses of the aorta to isoproterenol in naive and streptozotocin-induced diabetic rats. J Pharmacol Exp Ther 249: 890-894

13. Pfaffman M, Hilman R, Darby A (1980) Contractile relaxing activity of arterial smooth muscle from streptozotocindiabetic rats. Res Commun Chem Pathol Pharmacol 30: 283299

14. Colwell J, Halushka P, Sarji K, Lopes-Virella M, Sagel J (1979) Vascular disease in diabetes: pathophysiological mechanisms and therapy. Arch Int Med 139: 225-230

15. Chang K, Stevens W (1992) Endothelium-dependent increase in vascular sensitivity to phenylephrine in long-term streptozotocin diabetic rat aorta. Br J Pharmacol 107:983- -990

16. Pfaffman MA, Ball CR, Darby A, Hilman R (1982) Insulin reversal of diabetes-induced inhibition of vascular contractility in the rat. Am J Physiol 242: H490-H495

17. Mulhern M, Docherty J (1986) Effects of experimental diabetes on the responsiveness of rat aorta. $\mathrm{Br} \mathrm{J}$ Pharmacol 97: 1007-1012

18. Kyoung C, Stevens W (1992) Endothelium-dependent increase in vascular sensitivity to phenylephrine in long-term streptozotocin diabetic rat aorta. Br J Pharmacol107:983-990

19. Fortes Z, Leme J, Scivoletto R (1983) Vascular reactivity in diabetes mellitus: role of the endothelial cell. Br J Pharmacol 79: 771-781

20. Kappagoda T, Jayakody L, Rajotte R, Thomson A, Senaratne P (1989) Endothelium-dependent relaxation to acetylcholine in the aorta of streptozotocin induced diabetic-rat and the BB-diabetic rat. Clin Invest Med 12:187-193

21. Wakabayashi I, Katake K, Kimura N, Kakishita E, Nagai K (1986) Modulation of vascular tonus by the endothelium in experimental diabetes. Life Sci 40: 643-648

22. Mayhan WG (1989) Impairment of endothelium-dependent dilation of cerebral arterioles during diabetes mellitus. Am J Physiol 256: H621-H625

23. Oyama Y, Kawasaki K, Hattori Y, Kanno M (1986) Attenuation of endothelium-dependent relaxation in aorta from diabetic rats. Eur J Pharmacol 131: 75-78

24. Pieper G, Gross G (1988) Oxygen free radicals abolish endothelium-dependent relaxation in diabetic rat aorta. Am J Physiol 255: H825-H833

25. Pieper G, Mei D, Langenstroer P, O'Rourke S (1992) Bioassay of endothelium-derived relaxing factor in diabetic rat aorta. Am J Physiol 263: H676-H680

26. Matsuzaki T, Sakanashi M (1992) Comparison of the development of tolerance to nitroglycerin in aortic preparations isolated from non-diabetic and diabetic rats. Heart Vessels 7 : $1-7$
27. Clozel M, Kuhn H, Hefti F (1990) Effects of angiotensin converting enzyme inhibitors and of hydralazine on endothelial function in hypertensive rats. Hypertension 16: 532-540

28. Finta K, Fisher M, Lee L, Gordon D, Pitt B, Webb RC (1993) Ramipril prevents impaired endothelium-dependent relaxation in arteries from rabbits fed an atherogenic diet. Atherosclerosis 100: 149-156

29. Flower R (1974) Drugs which inhibit prostaglandin synthesis. Pharmacol Rev 267:33-67

30. Flemming W, Westfall D, De La Lande I, Jellett L (1972) Log-normal distribution of equieffective doses of norepinephrine and acetylcholine in several tissues. J Pharmacol Exp Ther 181: 339-345

31. Vanhoutte P, Auch-Schwelk W, Biondi M, Lorenz R, Schini V, Vidal J (1989) Why are converting enzyme inhibitors vasodilators? Br J Pharmacol 28: 95 S-104 S

32. Momose N, Fukou K, Morimoto S, Ogihara T (1993) Captopril inhibits endothelin-1 secretion from endothelial cells through bradykinin. Hypertension 21: 921-924

33. Wiemer G, Scholkens BA, Becker RH, Busse R (1991) Ramiprilat enhances endothelial autacoid formation by inhibiting breakdown of endothelium-derived bradykinin. Hypertension 18: 558-563

34. Mombouli J, Vanhoutte P (1991) Kinins and endotheliumdependent relaxations to converting enzyme inhibitors in perfused canine arteries. J Cardiovas Pharmacol 18: 926-927

35. Egleme C, Godfraind T, Miller RC (1984) Enhanced responsiveness of rat isolated aortae to clonidine after removal of endothelial cells. Br J Pharmacol 81: 16-18

36. Martin W, Furchgott R, Villani G (1986) Depression of contractile responses in rat aorta by spontaneously released endothelium derived relaxing factor. J Pharmacol Exp Ther 237: 529-538

37. Vane J, Anggard E, Botting R (1990) Regulatory functions of the vascular endothelium. N Eng J Med 323: 27-36

38. Beasley D (1990) Interleukin-1 and endotoxin activate soIuble guanylate cyclase in vascular smooth muscle. Am $\mathbf{J}$ Physiol 259: R38-R44

39. Busse R, Mulsch A (1990) Induction of nitric oxide synthase by cytokines in vascular smooth muscle cells. FEBS Letters 275: 87-90

40. Charpie J, Webb R (1993) Vascular myocyte-derived nitric oxide is an autocrine that limits vasoconstriction. Biochem Biophys Res Commun 194: 763-768

41. Sada T, Koike H, Ikeda M, Sato K, Ozaki H, Karaki H (1990) Cytosolic free calcium of aorta in hypertensive rats. Hypertension 16: 245-261

42. Ito K, Koike N, Miyamoto M, Urkawa N (1980) Long term blockade of angiotensin converting enzyme alters passive ion transport of vascular smooth muscle. Life Sciences 26: 1023 1027

43. Rosendorff C, Patton J, Radford H, Kalliatakis B (1992) $\alpha$ Adrenergic and angiotensin II pressor sensitivity in hypertensive patients treated with an angiotensin converting enzyme inhibitor. J Cardiovas Pharmacol 19(Suppl 6): S105S109

44. Tierney G, Marywood J, Stokes G (1989) An in vitro study of interactions between doxazosin and enalaprilat at vascular $\alpha_{1}$-adrenoceptors. Clin Exp Pharmacol Physiol 16: 329-332 